Marquette University

e-Publications@Marquette

Biological Sciences Faculty Research and

Publications

Biological Sciences, Department of

$9-2009$

\title{
The Tall Fescue Turf Grass Class I Chitinase Gene FaChit1 Is Activated by Fungal Elicitors, Dehydration, Ethylene, and Mechanical Wounding
}

Jian Wang

Key Laboratory of Resource Biology and Biotechnology in Western China

$\mathrm{Na}$ Tian

Key Laboratory of Resource Biology and Biotechnology in Western China

Xuan Huang

Key Laboratory of Resource Biology and Biotechnology in Western China

Li Yu Chen

Key Laboratory of Resource Biology and Biotechnology in Western China

Michael Schläppi

Marquette University, michael.schlappi@marquette.edu

See next page for additional authors

Follow this and additional works at: https://epublications.marquette.edu/bio_fac

Part of the Biology Commons

\section{Recommended Citation}

Wang, Jian; Tian, Na; Huang, Xuan; Chen, Li Yu; Schläppi, Michael; and Xu, Zi Qin, "The Tall Fescue Turf Grass Class I Chitinase Gene FaChit 1 Is Activated by Fungal Elicitors, Dehydration, Ethylene, and Mechanical Wounding" (2009). Biological Sciences Faculty Research and Publications. 737.

https://epublications.marquette.edu/bio_fac/737 


\section{Authors}

Jian Wang, Na Tian, Xuan Huang, Li Yu Chen, Michael Schläppi, and Zi Qin Xu

This article is available at e-Publications@Marquette: https://epublications.marquette.edu/bio_fac/737 


\section{Marquette University}

\section{e-Publications@Marquette}

\section{Biology Faculty Research and Publications/College of Arts and Sciences}

This paper is NOT THE PUBLISHED VERSION; but the author's final, peer-reviewed manuscript. The published version may be accessed by following the link in the citation below.

Plant Molecular Biology Reporter, Vol. 27, No. 3 (September 2009) : 305-314. DOI. This article is (C) Springer and permission has been granted for this version to appear in e-Publications@Marquette. Springer does not grant permission for this article to be further copied/distributed or hosted elsewhere without the express permission from Springer.

\section{The Tall Fescue Turf Grass Class I Chitinase Gene FaChit1 Is Activated by Fungal Elicitors, Dehydration, Ethylene, and Mechanical Wounding}

Jian Wang

Key Laboratory of Resource Biology and Biotechnology in Western China (Ministry of Education), Institute of Life Science, Northwest University, Xi'an, People's Republic of China

College of Agriculture and Life Sciences, AnKang University, Ankang, People's Republic of China

$\mathrm{Na}$ Tian

Key Laboratory of Resource Biology and Biotechnology in Western China (Ministry of Education), Institute of Life Science, Northwest University, Xi'an, People's Republic of China

Xuan Huang

Key Laboratory of Resource Biology and Biotechnology in Western China (Ministry of Education), Institute of Life Science, Northwest University, Xi'an, People's Republic of China

Li Yu Chen

Key Laboratory of Resource Biology and Biotechnology in Western China (Ministry of Education), Institute of Life Science, Northwest University, Xi'an, People's Republic of China

Michael Schläppi 
Department of Biological Sciences, Marquette University, Milwaukee, USA

\section{Zi Qin Xu}

Key Laboratory of Resource Biology and Biotechnology in Western China (Ministry of Education), Institute of Life Science, Northwest University, Xi'an, People's Republic of China

\section{Abstract}

The cDNA, genomic DNA, and promoter sequence of FaChit1, a class I chitinase gene from Festuca arundinacea, were isolated and characterized in the present work. The deduced amino acid sequence of FaChit1 contains the chitin binding, catalytic, and proline and glycine-rich domains characteristic for most class I chitinases, but no Cterminal extension region. FaChit1 is induced effectively by fungal elicitors, dehydration, and ethylene, but only slightly by mechanical wounding. To identify potential stress-related cis-acting elements, 5 ' sequences 935,651 , and 233 bp upstream of the FaChit1 start codon were fused to the GUS reporter gene and analyzed in transgenic tobacco. The results indicated that the $935 \mathrm{bp}$ fragment closely mirrored endogenous gene expression and that the 651 bp fragment was sufficient to direct reporter the gene expression in response to fungal elicitors, ethylene, dehydration, or mechanical wounding due to both known and presently uncharacterized cis-acting elements.

\section{Keywords}

Tall fescue (Festuca arundinacea) Class I chitinase Promoter activation Stress-induced gene Plant defense

\section{Abbreviations}

PCR Polymerase chain reaction

RACE Rapid amplification of CDNA end

MUG 4-Methylumbellifery I- $\beta$-D-glucuronide

GUS $\beta$-Glucuronidase

\section{Electronic supplementary material}

The online version of this article (doi: 10.1007/s11105-008-0086-8) contains supplementary material, which is available to authorized users.

\section{Introduction}

Chitinases play an important role in the plant defense system by degrading chitin, the main component of the cell wall of most fungi. The oligomeric degradation products act as fungal elicitors to stimulate further defense responses (Salzman et al. 2005). Plant chitinases are grouped into seven classes based on their structure (Gomez et al. 2002), among which classes I, II, and IV are similar, especially in the catalytic domain (Beintema 1994). A cysteine-rich domain, separated from a highly conserved catalytic domain (CD) by a hinge region (HR) containing variable number of proline and glycine residues, is essential for substrate binding (Iseli et al. 1993; Huet et al. 2008). A short carboxyl-terminal extension (CTE) specific to most class I chitinases is sufficient for vacuolar targeting.

The structures of classes I and II chitinase genes are diverse, and the copy number of them is variable in different species. Chitinase genes within each class reside at different chromosomal locations or cluster together at different locations of the same chromosome (Li et al. 1999). The diversification of these genes may provide more opportunities for the structural and functional evolution of chitinase genes in response to various 
pathogen infection, developmental regulations, and for recruitment of new functions (Li et al. 2001). The presence of multiple chitinase homologues in many plant species is consistent with the observation that evolution of disease resistance genes is generally faster than that of other plants genes (Richter and Ronald 2000).

In addition to a quick response to pathogen attack, chitinase genes are induced by a variety of abiotic stresses such as ozone, salt, drought, mechanical wounding, heavy metals, and general osmotic stress (Wu et al. 1999; Tateishi et al. 2001; Chujo et al. 2008). Pathogen attack generally leads to an increased amount of endogenous salicylic acid, jasmonic acid, or ethylene, which act as signaling molecules to activate both local and systemic defense responses (Thatcher et al. 2005). Consequently, chitinases are also upregulated by exogenous application of ethylene, salicylic acid, or jasmonic acid (Nakano et al. 2006; Fan et al. 2007).

To investigate the transcriptional regulation of chitinase genes during defense responses, promoters from various plant species were isolated and characterized (Hong and Hwang 2006). For example, the promoter of class I chitinase genes such as CHN48 from tobacco and ChtC2 from potato contain ethylene responsive GCC boxes (Shinshi et al. 1995; Ancillo et al. 2003). In addition, a W box element in the promoter of CHN48 containing the core sequence TGAC is responsible for the binding of WRKY homologues, suggesting that WRKY factors regulate the transcription of tobacco chitinase genes (Yamamoto et al. 2004).

In the present work, FaChit1, a class I chitinase gene from the tall fescue turf grass Festuca arundinacea, was isolated and characterized. Responses of FaChit1 to fungal elicitors, dehydration, mechanical wounding, and ethylene were analyzed, and several potential regulatory elements within the FaChit1 promoter were identified via deletion analysis. Our results indicated that the expression of FaChit1 is induced by multiple stresses, predominantly by fungal elicitors, which might contribute to the disease resistance of this important grass species.

\section{Materials and Methods}

\section{Growth Conditions, Stress Treatment, and Nucleic Acids Extraction}

Tall fescue grass cultivar "Ruby" was grown in a greenhouse at $25^{\circ} \mathrm{C}$ day and $20^{\circ} \mathrm{C}$ night temperatures. Fungal elicitor was prepared from chitosan (Sangon, ShangHai, China) as previously described (Mei et al. 2000). Plantlets were sprayed with $100 \mu \mathrm{g} / \mathrm{ml}$ elicitor and incubated in a greenhouse at $25^{\circ} \mathrm{C}$ for $24 \mathrm{~h}$. For dehydration treatment, plantlet roots were immersed in $300 \mathrm{mmol} / \mathrm{I}$ mannitol solution for $24 \mathrm{~h}$. For ethylene treatment, plantlets were sprayed with a $1 \mathrm{mg} / \mathrm{ml}$ ethephon aqueous solution and sealed in plastic bags for $24 \mathrm{~h}$. For wounding treatment, mature leaves and roots were cut into strips (approximately $5 \mathrm{~cm}$ in length) and kept moist on wet filter paper for $24 \mathrm{~h}$ at room temperature. Treated leaves and roots were harvested after $24 \mathrm{~h}$. Genomic DNA was extracted from leaves using the CTAB method as previously described by (Stewart and Via 1993). Total RNA was extracted as previously described (Bubier and Schläppi 2004) and dissolved in RNA-free water. RNA samples were immediately treated with DNase I for $10 \mathrm{~min}$ to eliminate DNA and frozen at $-80^{\circ} \mathrm{C}$.

\section{Isolation of FaChit1 cDNA and Genomic DNA}

A pair of degenerate primers (set 1 , supplementary Table $\mathrm{S} \underline{1}$ ) was designed based on two amino acid motifs, CPNCLC and DCYSQR, which are highly conserved in class I chitinases of gramineous species. CDNA was synthesized from $1 \mu \mathrm{g}$ total RNA by reverse transcription using the RevertAid ${ }^{\mathrm{TM}}$ first-strand cDNA synthesis kit (Fermentas, Lithuania, USA). cDNA was amplified using $1 \mu$ of first-strand cDNA, 400 pM of each dNTP, 0.4 pM degenerate primers, and 2.5 units of Taq DNA polymerase (Takara, DaLian, China). PCR products were ligated into the pMD18-T vector (Takara, DaLian, China) and sequenced. Two sets of nested primers (sets 2 and 3, supplementary Table S1) were designed based on the isolated cDNA fragment, and 3 '- and 5'-end cDNA sequences were obtained using a $3^{\prime} / 5^{\prime}$ RACE kit according to the manufacturer's instruction (Takara, DaLian, 
China). The complete coding region of FaChit1 was amplified from full-length CDNA and genomic DNA (primer set 4, supplementary Table S1). DNA sequences were analyzed using DNAStar (Version 5.0). Homology searches were performed using the BLAST algorithm (http://www.ncbi.nlm.nih.gov/BLAST).

\section{Isolation of the Fachit1 Promoter by Genome Walking}

Genomic DNA was cut with $50 \mathrm{U}$ of four blunt-end restriction enzymes (Dral, EcoRV, Scal, and Pvull) and used to construct adapter-ligated genomic libraries. The adapter was prepared by boiling a mixture containing $25 \mu \mathrm{mol} / \mathrm{I}$ long adapter oligonucleotide 5'-GTAATACGACTCACTATAGGGCACGCGTGGTCGACGGCCC GGGCTGGT-3' and $25 \mu \mathrm{mol} / /$ short adapter oligonucleotide $5^{\prime}-\mathrm{PO}_{4}$-ACCAGCCC-NH ${ }_{2}-3^{\prime}$ in a water-bath for 2 min and gradually cooling to room temperature. Ligation was carried out with $10 \mu$ digested DNA ( $50 \mathrm{ng} / \mu \mathrm{l}), 1.0 \mu \mathrm{l} \mathrm{T4}$ DNA ligase, and $2.0 \mu \mathrm{l}$ of $25 \mu \mathrm{M}$ adapter overnight at $16^{\circ} \mathrm{C}$ in a final volume of $20 \mu \mathrm{l}$. Phosphorylation of the $5^{\prime}$-end allowed the adapter to be ligated to the digested genomic DNA by T4 DNA ligase, and the amine group of the $3^{\prime}$-end prevented extension from the $3^{\prime}$ end by Taq polymerase in subsequent PCR reactions. For genome walking, $5^{\prime}$ end cDNA specific primers PGSP1 and PGSP2 (set 5, supplementary Table S1) and genome walker kit specific primers AP1 and AP2 (set 6, supplementary Table S1) were used, and PCR reactions were performed according to the BD Genome Walker ${ }^{\mathrm{TM}}$ Universal Kit's instruction (Clontech, Palo Alto, CA, USA). The obtained promoter sequences were analyzed using the PLACE database (http://www.dna.affrc.go.jp/htdocs/PLACE/).

\section{DNA and RNA gel Blot Analyses}

Tall fescue genomic DNA (20 $\mu \mathrm{g}$ ) was digested to completion with BamHI, Kpnl, HindIII, Xbal, EcoRV, or Dral. Digested genomic DNA was fractionated on a $0.7 \%(w / v)$ agarose gel, blotted onto a nylon membrane (Hybond $\mathrm{N}^{+}$) in 10x sodium chloride/sodium citrate and crosslinked using $120 \mathrm{~mJ}$ UV light (Sambrook and Russell 2001). A $560 \mathrm{bp}$ Fachit1 5' upstream fragment and a $500 \mathrm{bp}$ coding region fragment were amplified from pMD18-T plasmids and labeled with DIG-11-UTP. Southern blotting was performed using the DIG-High prime DNA Labeling and Detection Starter Kit I (Roche Diagnostics, Mannheim, Germany) according to the manufacturer's instructions.

Total RNA was extracted from young leaves and roots of stress-treated tall fescue plants or leaves of transgenic tobacco plants. Thirty microgram of total RNA was separated on a 1.5\% agarose gel containing $2.2 \mathrm{~mol} / \mathrm{l}$ of formaldehyde and transferred onto nylon membranes according to standard protocols (Sambrook and Russell 2001). Hybridization and signal detection procedures using a $500 \mathrm{bp}$ coding region probe were as described above for DNA gel blot analyses. To detect GUS transcripts in transgenic tobacco, a 400 bp coding sequence of GUS was amplified from pBI121, labeled with DIG-11-UTP, and used as hybridization probe as described

\section{FaChit1 Promoter-GUS Analysis in Transgenic Tobacco Plants}

To fuse a PCR-amplified promoter fragment consisting of 935 bp sequences upstream of the FaChit1 start codon to the $\beta$-glucuronidase (GUS) reporter gene, HindIII and BamHI sites were included in the forward and reverse primers (set 7, supplementary Table S 1 ), respectively. The amplified fragment was used to replace the CaMV35S promoter upstream of GUS in the plant transformation vector pBI121 (Clontech). The resulting construct was designated as pFaChit1P-I (supplementary Fig. S11). Two deletion constructs (651 and 233 bp fragments) designated as pFaChit1P-II and pFaChit1P-III (supplementary Fig. S1) were created from pFaChit1P-I using nested primers (set 9, supplementary Table S1 ). Plasmids constructs were validated using FaChit1 promoter and GUS specific primers (set 8, supplementary Table $\mathbf{S} 1$ ) and sequenced from both ends. Each promoter-GUS fusion construct was introduced into Agrobacterium tumefaciens strain LBA4404 via the freeze-thaw method previously described (Bevan 1984). Young leaves of tobacco plants (Nicotiana tobacum) were transformed, and transgenic plants were regenerated using the standard leaf disc method (Rogers et al. 1988). Explants from individual transformants were propagated in vitro and used for stress treatments and RNA isolation. 
GUS activity driven by FaChit1 promoter in transgenic tobacco was measured as previously described (Jefferson et al. 1987). Briefly, young leaf tissues were homogenized in liquid nitrogen and $1 \mathrm{ml}$ extraction buffer (pH 7.0) containing $50 \mathrm{mM} \mathrm{NaH}_{2} \mathrm{PO}_{4}, 10 \mathrm{mM}$ EDTA, 0.1\% Triton X-100, 0.1\% (w/v) sodium laurylsarcosine, and $10 \mathrm{mM} \beta$ mercaptoethanol was added, mixed in a microtube, and centrifuged at $4^{\circ} \mathrm{C}$ for $10 \mathrm{~min}$ at $12,000 \times \mathrm{g}$. Supernatant $(0.1 \mathrm{ml})$ was added to $0.9 \mathrm{ml}$ of fluorogenic reaction buffer containing $1 \mathrm{mM}$ 4-methylumbelliferyl I- $\beta$-Dglucuronide (MUG; Sangong, Shanghai, China). Protein concentration in the supernatant was measured with bovine serum albumin as a standard using the method described by Bradford (1976).

\section{Results}

\section{Structure of the FaChit1 Gene}

An 849 bp fragment was amplified from $F$. arundinacea (tall fescue) cDNA using degenerate primers with homology to plant chitinases. BLAST analysis showed that this fragment shared high sequence similarity with class I chitinases from gramineous plants. Therefore, a full-length cDNA of $F$. arundinacea Chitinase 1 (FaChit1) was obtained using 5' RACE and 3' RACE. The cDNA had a probable transcription initiation site (G) located 58 bp upstream of the ATG start codon and a polyA tail at the $3^{\prime}$ end (Fig. 1a). The full-length open reading frame contained 951 base pairs and encoded a deduced class I chitinase containing 317 amino acids with a calculated molecular mass of $33.24 \mathrm{kDa}$ and a p/ of 7.91, which was consistent with the properties of most previously published plant class I chitinases. The sequence has been deposited into the GenBank database (accession number EU837265). 
(a)

GACACTAGCTAGCTAGCTGCAGCAAAGCTCGAGCGGGTTCGTCGGCTACATTGCCACC ATG ATG AGA GGA CTT TCG GTG GTG GCC ATC CTG GCC GCG GCC TTC GCC GTG $\begin{array}{llllllllllllllllll} & M & M & R & G & \text { L } & \text { S } & \text { V } & \text { V } & \text { A } & \text { I } & \text { L } & \text { A } & \text { A } & \text { A } & \text { F } & \text { A } & \text { V }\end{array}$ TCT GCG CAC GCC CAG CAG TGT GGC TCG CAG GCC GGC GGC GCG ACG TGC GCC $\begin{array}{llllllllllllllllllll}\mathrm{S} & \mathrm{A} & \mathrm{H} & \mathrm{A} & \mathrm{Q} & \mathrm{Q} & \mathrm{C} & \mathrm{G} & \mathrm{S} & \mathrm{Q} & \mathrm{A} & \mathrm{G} & \mathrm{G} & \mathrm{A} & \mathrm{T} & \mathbf{C} & \mathbf{A}\end{array}$

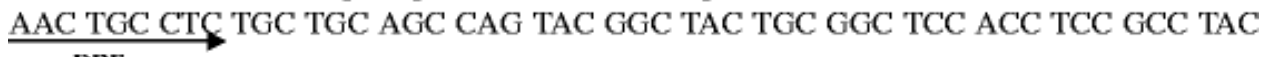
$\begin{array}{lllllllllllllllllll}\mathbf{N} & \mathbf{C} & \mathbf{L} & \mathbf{C} & \mathrm{C} & \mathrm{S} & \mathrm{Q} & \mathrm{Y} & \mathrm{G} & \mathrm{Y} & \mathbf{C} & \mathrm{G} & \mathrm{S} & \mathrm{T} & \mathrm{S} & \mathrm{A} & \mathrm{Y}\end{array}$ TGC GGC GCC GGC TGC CAG AGC CAG TGC AAC GGC TGC GGC GGC ACG CCG ACG $\begin{array}{lllllllllllllllllll}C & G & A & G & C & Q & S & \text { Q } & \text { C } & \text { N } & \text { G } & \text { C } & \text { G } & \text { G } & \text { T } & \text { P } & \text { T }\end{array}$ CCG ACT CCC TCC GGC GGC GTG TCC TCC ATC ATA TCC CAG TCG CTC TTC GAC

$\begin{array}{lllllllllllllllllll}\mathrm{P} & \mathrm{T} & \mathrm{P} & \mathrm{S} & \mathrm{G} & \mathrm{G} & \mathrm{V} & \mathrm{S} & \mathrm{S} & \mathrm{I} & \mathrm{I} & \mathrm{S} & \mathrm{Q} & \mathrm{S} & \mathrm{L} & \mathrm{F} & \mathrm{D}\end{array}$ CAG ATG CTG CTG CAC CGC AAC GAC GCG GCG TGC CCG GCC AAG GGA TTC TAC

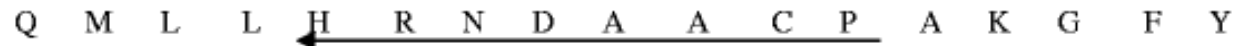
AAC 4 TAC AAC GCC TTC ATC GCC GCC GCT AAC TTC TTC TCG GGC TTC GCG ACC $\mathbf{S}^{\prime} \mathrm{GSP}_{2} \quad \mathrm{PGSP}_{1}$

$\begin{array}{llllllllllllllllll}\mathrm{N} & \mathrm{Y} & \mathrm{N} & \mathrm{A} & \mathrm{F} & \mathrm{I} & \mathrm{A} & \mathrm{A} & \mathrm{A} & \mathrm{N} & \mathrm{F} & \mathrm{F} & \mathrm{S} & \mathrm{G} & \mathrm{F} & \mathrm{A} & \mathrm{T}\end{array}$ ACG GGC AGC ACC GAC GTC AGG AAG CGC GAG GTG GCC GCC TTC CTC GCC CAG $\begin{array}{lllllllllllllllllllll}T & G & S & T & D & V & R & K & R & E & V & A & A & F & L & A & Q\end{array}$ ACC TCC CAC GAG ACC ACC GGC GGG TGG GCC ACG GCG CCC GAC GGC CCC TAC $5^{\prime} \mathrm{GSP}_{1}$

$\begin{array}{llllllllllllllllll}\mathrm{T} & \mathrm{S} & \mathrm{H} & \mathrm{E} & \mathrm{T} & \mathrm{T} & \mathrm{G} & \mathrm{G} & \mathrm{W} & \mathrm{A} & \mathrm{T} & \mathrm{A} & \mathrm{P} & \mathrm{D} & \mathrm{G} & \mathrm{P} & \mathrm{Y}\end{array}$ TCG TGG GGC TAC TGC TTC AAG CAG GAG CAA GGC GCC ACG TCC GAC TAC TGC $\begin{array}{lllllllllllllllll}S & W & G & Y & C & F & K & Q & E & Q & G & A & T & S & D & Y & C\end{array}$ TCG CCG AGC TCT CAG TGG CCG TGC GCG GCG GGG AAG AAG TAC TAC GGC CGC $\begin{array}{llllllllllllllllll}S & P & S & S & Q & W & P & C & A & A & G & K & K & Y & Y & G & R\end{array}$ GGG CCC ATC CAG ATC TCC TAC AAC TAC AAC TAC GGG CCG GCG GGG AAG GCC $\begin{array}{lllllllllllllllll}G & P & I & Q & I & S & Y & N & Y & N & Y & G & P & A & G & K & A\end{array}$ ATC GGC AGC GAC CTG CTC GGG AAC CCG GAC CTG GTG GCC ACG GAC GCC ACT $\begin{array}{lllllllllllllllll}\text { I } & G & S & D & \text { L } & \text { L } & G & \text { N } & \text { P } & \text { D } & \text { L } & \text { V } & \text { A } & \text { T } & \text { D } & \text { A } & \text { T }\end{array}$ GTG TCG TTC AAG ACG GCG CTG TGG TTC TGG ATG ACG CCG CAG TCG CCC AAG ${ }^{\prime}$ 'GSP $_{1}$

$\begin{array}{lllllllllllllllllll}\mathrm{V} & \mathrm{S} & \mathrm{F} & \mathrm{K} & \mathrm{T} & \mathrm{A} & \mathrm{L} & \mathrm{W} & \mathrm{F} & \mathrm{W} & \mathrm{M} & \mathrm{T} & \mathrm{P} & \mathrm{Q} & \mathrm{S} & \mathrm{P} & \mathrm{K}\end{array}$ CCG TCC AGC CAC AAC GTG ATC ACG GGC CGG TGG AGC CCC TCG GCC GCG GAC ${ }^{\prime} \mathrm{GSP}_{2}$

$\begin{array}{lllllllllllllllll}\mathrm{P} & \mathrm{S} & \mathrm{S} & \mathrm{H} & \mathrm{N} & \mathrm{V} & \mathrm{I} & \mathrm{T} & \mathrm{G} & \mathrm{R} & \mathrm{W} & \mathrm{S} & \mathrm{P} & \mathrm{S} & \mathrm{A} & \mathrm{A} & \mathrm{D}\end{array}$ AAG GCA GCC GGG AGG GTG CCC GGG TAC GGC GTG ATC ACC AAC ATC ATC AAC

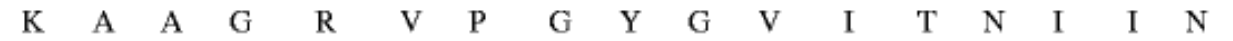
GGC GGG CTC GAG TGC GGC AAG GGG CAG GAC AAC CGC GTC GCC GAC AGG ATC $\begin{array}{lllllllllllllllllllll}\text { G } & G & \text { L } & \text { E } & \text { C } & \text { G } & \text { K } & \text { G } & \text { Q } & \text { D } & \text { N } & \text { R } & \text { V } & \text { A } & \text { D } & \text { R } & \text { I }\end{array}$ GGC TTC TAC AAG CGC TAC TGC GAC CTC CTC GGC GTC AGC TAC GGA GAC AAC $\begin{array}{llllllllllllllllll}G & F & Y & K & R & Y & C & D & \text { L } & \text { L } & \text { G } & \text { V } & \text { S } & \text { Y } & \text { G } & \text { D } & \text { N }\end{array}$ CTC GAC TGC TAC AGC CAG AGG CCG TTC GCG TAA " GCCTGCGCGGCCGGCAAC

$\begin{array}{llllllllllll}\text { L } & \mathbf{D} & \mathbf{C} & \mathbf{Y} & \mathbf{S} & \mathbf{Q} & \mathbf{R} & \mathrm{P} & \mathrm{F} & \mathrm{A}\end{array}$

CTGCTAATAAAAATCTCTCTACATACTGCTGTAACTATGGCGTTGCAAACATGAAACTT GAGTGAAAAAGTGTGACCCCTCACAAGAGATGCAATATTGCAATCCATTAATGAAATA AACGATTTGGGCCAAAAAAAAAAAAAA 
(b)

AAAATATGGCACACCAATTAATGAGGTGAGAGATGAGAGTGGTATCATAATATGATA

$\mathbf{- 9 3 5}$

CCGTATCATAGCACGTAAAACCAGAAACTCAATAGCAAAAACATCATGTACACCAAT ÁBRE-like

TTGCATTGAGATTCTACAAAACATTAAATATGATGATACTATGATACTATCTTATGATAC MYCATERD1

TATGCATTGTGGGGGTAGTATCATGTGCATGATACTAGTGTATGATACTTCTCATTGTG

ACTAGTCGCAAACAGCAACGGGTACAAAGAGTTGAATTCGAACATGTCCAATGACC MYBCORE

$\Delta-651$

AATGCATCTACAGAAAGAACGGATGGAATTCCATGCATGAAAGCTACATCCATATCTA

TCCCATTAGTGCAATGCATGGATATGCGCCATCTATATATCCGCGAAAATTCCACGTCC
PALBOXAPC $\underset{\text { GTCCACCCATTGATGCGGCGAAGTTTGATCGCACGCCAAAGGCTGAGCTGGTGCAC }}{\stackrel{\text { ABRE-like }}{\longrightarrow}}$ GCACACGAAGCGATCGAGGAGAAAAATCTGACCTACAGAGCAACCGAATTTGACTT GACACGATTTTTCCACGCTTGCCTCCAGCCCAGCATTTCCATGCCGATCAACGTCGTC MYCCONSENSUSAT CCTTACCCCGTGAATCGTGCAAACGGCATGTGCATGCTTGCCCTTCCACGAGTGGTA TCTCATCCGTACGTAGCTAGCCTAGCAAGTAACCCTCCAATTTGCGGAGACCCGAGC $\underset{\text { WRKY710S }}{\longrightarrow}$

ATGCATGAATCTACTAGATCGCTGACGAGATCTGCCCAACTCATCGTAGATTAGACCG

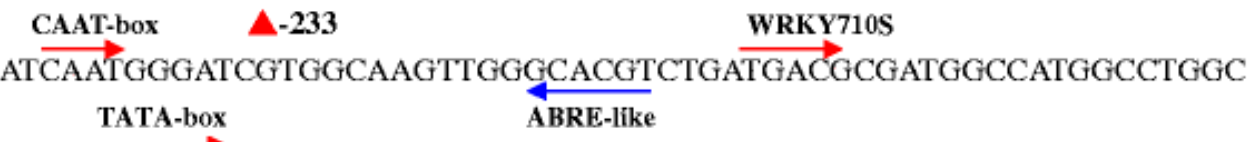
GAGCTATATAAGGACCTGCAGCATACAATCTTCTTCCACACACACCACTACACACGA GCAGTGTCCCATTGCGACACTAGCTAGCTAGCTGCAGCAAAGCTCGAGCGGGTTCG $+1$

TCGGCTACATTGCCAGG $\underline{\underline{A T G}}$

Start codon

Fig. 1 Sequence information of the FaChit1 gene. (a) cDNA and deduced amino acid sequences of FaChit1. Arrows show the primer locations used in different experiments. Two motifs used for designing degenerate primers are indicated in bold. The stop code is marked with the number sign. The translation start codon and polyadenylation signal are marked in bold and in italics, respectively. (b) Nucleotide sequence of the $5^{\prime}$ upstream region of FaChit1 and location of putative cis-acting promoter elements. MYCATRD22 and ABRE like are found in ABA-responsive genes (Busk and Pages 1998; Nakashima et al. 2006) and MYCATERD1 in dehydration stress-responsive genes (Tran et al. 2004), MYBCORE and MYCCONSENSUSAT are binding sites for MYB factors (Urao et al. 1993; Chinnusamy et al. 2004), WBOXATNPR1 is a binding site for a pathogen-induced transcription factor (Chen and Chen 2002), WBOXNTCHN48 is a cis-acting element of the class I chitinase gene CHN48, WRKY710S is a binding site for WRKY transcription factors (Eulgem et al. 1999), and PALBOXAPC is a GT-1 motif involved in pathogen- and salt-induced gene expression (Park et al. 2004); -233, -651, and -935 indicate the end points of promoter deletion fragments fused to the GUS reporter gene

To investigate the structure of FaChit1, genomic DNA corresponding to its coding region was cloned and no intron was found. To investigate its putative promoter, a 5'-flanking region containing 935 bp sequences upstream of the FaChit1 start codon was isolated from tall fescue genomic DNA using step-down PCR. Sequence analysis of this FaChit1 promoter fragment using the PLACE program identified several conserved motifs 
responsible for the transcriptional regulation in most eukaryotic genes (Fig. 1 b). Typical TATA (TATATAA) and CAAT (CCAATT) boxes were found 120 and 259 bp upstream of the start codon, respectively. Several potential cis-acting elements associated with plant hormone and stress-related responses were located within the FaChit1 promoter, including nine MYB transcription factor binding sites (one MYB2CONSENSUSAT, two MYB cores, three MYBCOREA TCYCB1, and MYBST1), eight MYC transcription factor binding sites (two MYCATERD1, two MYCATRD22, and four MYCCONSENSUSAT), nine W boxes (one WBOXNTCHN48, two WBOXATNPR1, two WBOXHVISO1, and four WBOXNTERF3), seven WRKY71OS, and four ABRE elements, indicating that FaChit1 expression might be regulated by various cis-acting elements and their corresponding trans-acting factors.

To determine the copy number of FaChit1, tall fescue Genomic DNA was digested with BamHI, Kpnl, HindIII, Xbal, EcoRV, or Dral. These enzymes have no internal restriction sites in the FaChit1 promoter and coding regions. DNA gel blot analyses were carried out with a 560 bp probe corresponding to $5^{\prime}$ upstream sequence and a 500 bp probe corresponding to the catalytic domain of the FaChit1 coding region. As shown in Fig. $\underline{2}$, two main bands were detected with the 5 ' upstream sequence probe, suggesting that tall fescue possessed two copies of FaChit1. By contrast, the 500 bp sequence corresponding to the catalytic domain of the FaChit1 coding region hybridized to approximately eight to nine HindIII fragments. These results suggested that the tall fescue genome contains a small chitinase gene family.

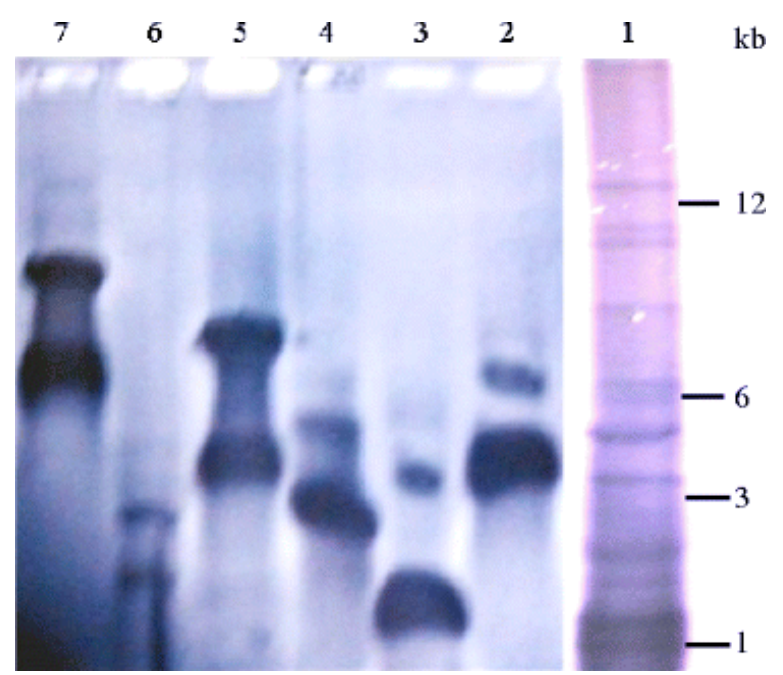

Fig. 2 DNA gel blot analysis to estimate the FaChit1 copy number in the tall fescue genome. Lane 1, genomic was digested with HindIII and hybridized with a DIG-labeled 500 bp PCR fragment corresponding to the FaChit1 coding region; lanes 2-7, genomic DNA was digested with BamHI, Kpnl, HindIII, Xbal, EcoRV, or Dral, respectively, and hybridized with a DIG-labeled 560 bp PCR fragment corresponding to the $5^{\prime}$ upstream region of FaChit1. DNA sizes are indicated on the right

\section{Analysis of the Deduced FaChit1 Protein Sequence}

BLAST searches indicated that FaChit1 is closely related to a class I chitinase gene from Poa pratensis (AAF04454), sharing with it $87 \%$ sequence identity and $92 \%$ similarity. As shown in Fig. $3 a$, FaChit1 has three conserved amino acid motifs, a chitin binding domain (CBD), a proline and glycine-rich HR, and a CD. Consistent with other plant class I chitinases, no deletion was observed in the CD of FaChit1. As shown in Fig. $\underline{3} b$, six conserved amino acid residues, $S_{40}, Y_{42}, G_{43}, Y_{44}, G_{46}$, and $Y_{51}$, are found in the CBD; five conserved amino acid residues, $E_{140}, E_{162}, Q_{191}, S_{193}$, and $N_{272}$ are found in the $C D$; and five glycines and three prolines are found in the HR. 
(a)
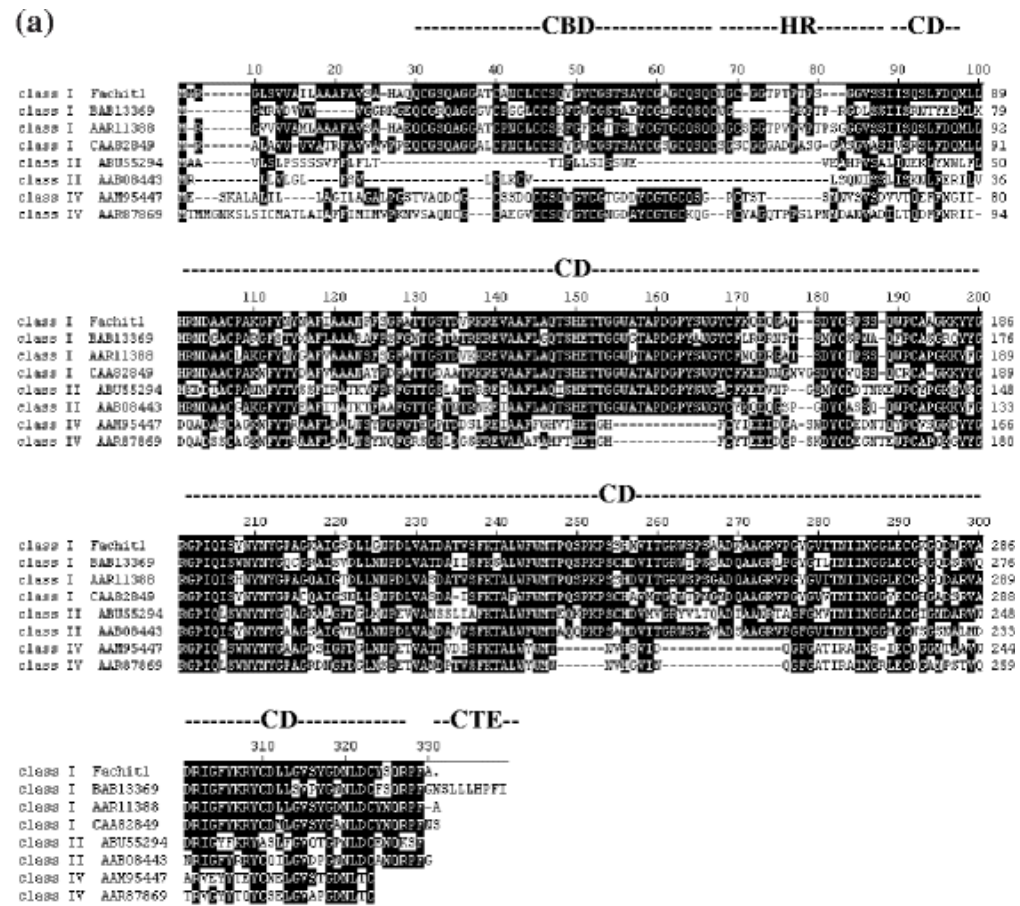

(b)

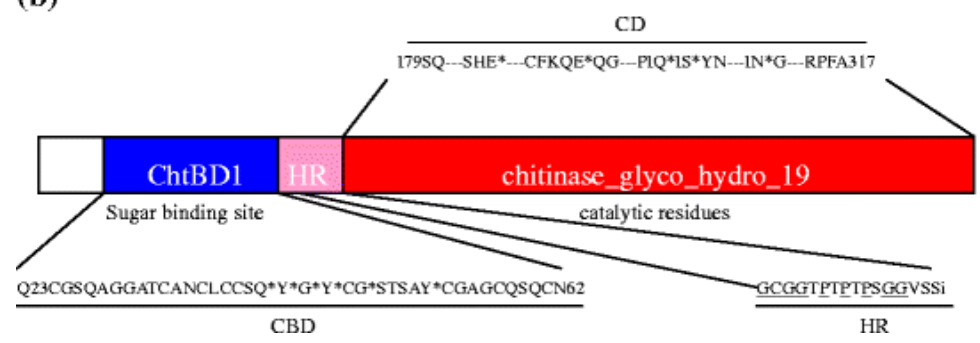

Fig. 3 Sequence alignment and domain structure of the FaChit1 protein. a Multiple alignment of FaChit1 with representative of classes I, II, and IV plant chitinases. The CBD, CD, HR, and CTE are indicated by dotted lines. BAB 13369, AAR11388, and CAA82849 are class I chitinases from Psophocarpus tetragonolobus, Triticum aestivum, and Oryza sativa, respectively; ABU55294 and AAB 08443 are class II chitinases from Fragaria $x$ ananassa and Lycopersicon esculentum, respectively; AAM95447 and AAR87869 are class IV chitinases from Vitis vinifera and Medicago truncatula, respectively. Conserved amino acids are shaded in black. $\mathbf{b}$ Graphic representation of the FaChit1 CBD and CD identified through CDS search in GenBank. CBD, HR, and CD are marked in blue, pink, and red, respectively. Conserved amino acid residues assumed to contribute to chitin binding and catalytic functions are marked with an asterisk. Conserved proline- and glycine-rich regions in the HR are underlined

\section{Expression Analysis of FaChit1}

To determine the expression profile of FaChit1 mRNA under different stress conditions, RNA gel analyses using a FaChit1 coding region probe were done. As shown in Fig. 4, FaChit1 mRNA was barely detectable in leaves and roots of untreated plants. By contrast, high amounts of FaChit1 mRNA were detected in leaves and roots treated with fungal elicitors. FaChit1 expression was also induced in both tissues by ethylene and mannitol, and to a lesser degree, by mechanical wounding in roots, but not in leaves. 
(a)
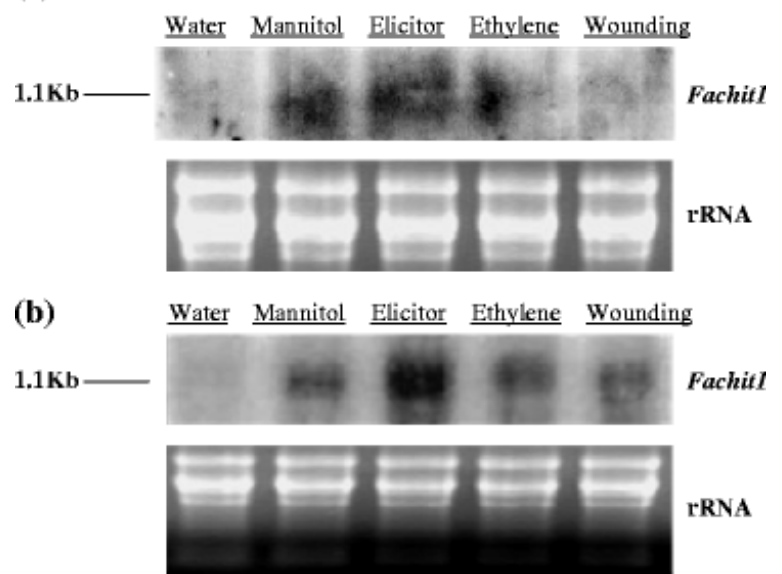

Fig. 4 RNA gel blot analysis of Fachit1 mRNA abundance in tall fescue roots (a) and leaves (b) in response to pathogen $(100 \mu \mathrm{g} / \mathrm{ml}$ fungal elicitor), dehydration (300 mM mannitol), ethylene $(1 \mathrm{mg} / \mathrm{ml})$, and wound (mechanical wounding) stress treatments. Each lane was loaded with $20 \mu \mathrm{g}$ of total RNA. Ribosomal RNA band were visualized in the agarose gel by ethidium bromide staining to show equal loading. Approximate size of the FaChit1 mRNA is indicated

To further investigate the regulation of FaChit1, activation of different promoter fragments (see Fig. 1 b) by fungal elicitors, dehydration, mechanical wounding, and ethylene were analyzed in transgenic tobacco using transcriptional fusions of FaChit1 $5^{\prime}$ upstream sequences to the GUS reporter gene. The sequence integrity of independent transgenic lines containing different promoter fragments was verified using PCR and DNA gel blot analyses (data not shown). As shown in Fig. $\underline{5}$ a, compared to mock-treated controls, the 935 and 651 bp DNA sequences upstream of the FaChit1 start codon conferred 6.5- and 5.1-fold inductions, respectively, of GUS activity in response to a 24-h treatment with fungal elicitors, which was in agreement with the RNA gel blot analyses results (Fig. 4). However, no induction of GUS activity could be detected in transgenic tobacco leaves containing the $233 \mathrm{bp}$ upstream sequence. To determine the effect of dehydration stress, transgenic tobacco leaves were treated with mannitol for $24 \mathrm{~h}$. As shown in Fig. $\underline{5} \mathrm{~b}$, compared to mock-treated controls, GUS activities were 5.4-, 4.75-, and 2.25-fold induced in leaves of tobacco harboring the 935, 651, and $233 \mathrm{bp}$ upstream sequences, respectively. As shown in Fig. $\underline{5} c$, compared to mock treatment, spraying of plants with ethylene increased GUS activity 5.0- and 2.5-fold in leaves of transgenic tobacco harboring the 935 and $651 \mathrm{bp}$ sequences, respectively, but no induction of GUS activity could be detected in transgenic tobacco leaves containing the $233 \mathrm{bp}$ upstream sequence. As shown in Fig. $\underline{5} \mathrm{~d}$, compared to mock treatment, GUS activity could also be induced moderately 2.4- and 2.1-fold, respectively, in response to mechanical wounding in leaves containing the 935 and 651 bp sequences, but not in plants with the $233 \mathrm{bp}$ upstream sequence. 

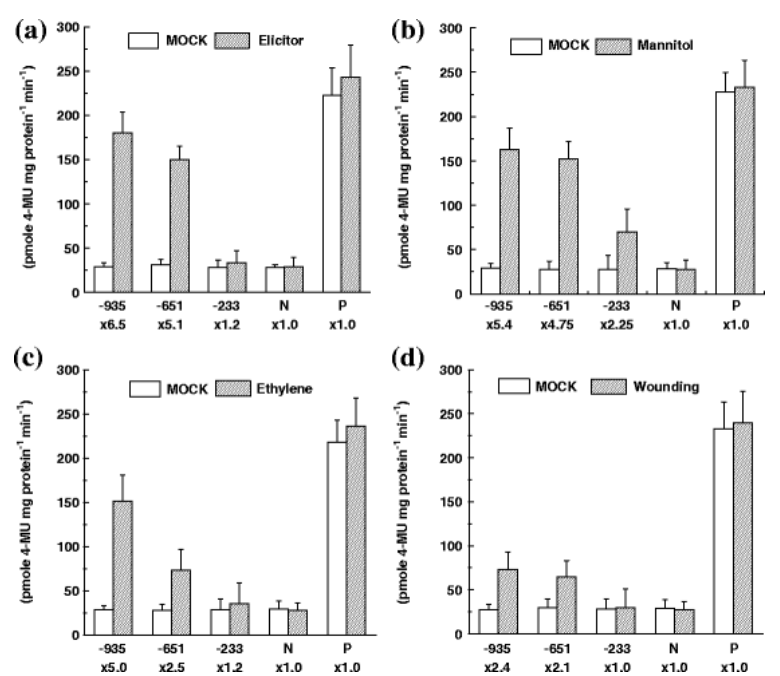

Fig. 5 Analysis of GUS activity in transgenic tobacco leaves containing FaChit1 $5^{\prime}$ upstream regions fused to the GUS reporter gene after $24 \mathrm{~h}$ of different stress treatments: a $100 \mu \mathrm{g} / \mathrm{ml}$ fungal elicitor, b $300 \mathrm{mM}$ mannitol, c $1 \mathrm{mg} / \mathrm{ml}$ ethylene, and $\mathrm{d}$ mechanical wounding. $\mathrm{ddH}_{2} \mathrm{O}$ was used as mock treatment. Specific GUS activity was measured fluorometrically and expressed as picomoles 4-methylumbelliferone $(M U)$ per milligram protein per minute. The $x$ value indicates fold increases of GUS activity after stress treatments relative to mock controls. $N$, negative control (untransformed wild-type tobacco); $P$, positive control (transgenic tobacco expressing GUS from the constitutive CaMV 35 S promoter); $-233,-651,-935$, different 5 ' regions upstream from the FaChit1 start codon fused to GUS (see Fig. 1 b). Data are means \pm standard deviations of at least three assays using one $(-233)$ or two $(-651,-935)$ independent transformants

To determine whether the observed GUS activity was in agreement with the relative abundance of GUS reporter gene transcripts, RNA gel blot analyses using stress-treated material from transgenic tobacco leaves harboring the 935 bp sequence upstream of the FaChit1 start codon were done. As shown in Fig. $\underline{6}$, the relative amount of GUS mRNA correlated well with the relative abundance of endogenous transcripts (Fig. 4 ) and was in agreement with the observed GUS enzyme activities of the 935 bp construct (Fig. $\underline{5}$ ).

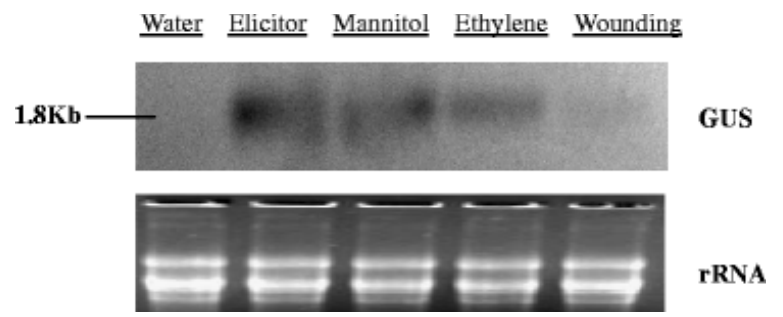

Fig. 6 RNA gel blot analysis of GUS mRNA abundance in leaves of transgenic tobacco plants containing the -935 FaChit1 5' upstream region fused to the GUS reporter gene after $24 \mathrm{~h}$ of different stress treatments: a $100 \mu \mathrm{g} / \mathrm{ml}$ fungal elicitor, b $300 \mathrm{mM}$ mannitol, c $1 \mathrm{mg} / \mathrm{ml}$ ethylene, and d mechanical wounding. $\mathrm{dd}_{2} \mathrm{O}$ was used as mock treatment. Each lane was loaded with $20 \mu \mathrm{g}$ of total RNA extracted from two independent transformants. Ribosomal RNA band was visualized in the agarose gel by ethidium bromide staining to show equal loading. Approximate size of the GUS mRNA is indicated

\section{Discussion}

Attack of plants by pathogens activates a complex network of signal transduction pathways, which results in the expression of a large number of defense genes such as chitinases (Somssich and Hahlbrock 1998;

Glazebrook 2001). To gain a better understanding of the defense mechanism of the tall fescue turf grass $F$. 
arundinacea in response to pathogens as well as different environmental stresses, the chitinase gene FaChit1 was isolated from the cultivar Ruby and characterized in this work.

Our genomic DNA gel blot analyses indicated that FaChit1 belongs to a multigene family, which has been previously observed for chitinase genes in other plant species. The presence of multiple chitinase homologues in many plant species, for instance in Balsam pear or rice, suggests that a diversification of these genes might counteract the rapid evolution of pathogens (Takakura et al. 2000; Xiao et al. 2007).

Consistent with other class I chitinases, FaChit1 has conserved glutamate $(G)$ and cysteine $(C)$ residues in its predicted active site $\left(\mathrm{G}_{43}, \mathrm{G}_{46}\right.$, and $\mathrm{C}_{24}, \mathrm{C}_{26}, \mathrm{C}_{29}, \mathrm{C}_{31}, \mathrm{C}_{32}, \mathrm{C}_{45}, \mathrm{C}_{52}, \mathrm{C}_{54}, \mathrm{C}_{57}$, respectively). The nine $\mathrm{C}$ residues are thought to form disulfide bridges (Beintema 1994). In addition, FaChit1 has other conserved amino acids ( $E_{140}$, $\mathrm{E}_{162}, \mathrm{Q}_{191}, \mathrm{~S}_{193}$, and $\mathrm{N}_{272}$ ) believed to be important for the catalytic activity of class I chitinases (Fukamizo 2000; Hahn and Henning 2000).

A number of cis-acting elements such as WRKY binding sites (W boxes) with a TGAC core sequence were shown to be associated with genes involved in the plant defense response against pathogens (Chen et al. 2002; Dong et al. 2003; Xu et al. 2006). For example, a W box elicitor response element in the promoter of the tobacco class I chitinase gene CHN5O is specifically bound by pathogen-induced TDBA12 and purified WRKY proteins (Yang et al. 1999). In the present work, a 233 bp DNA sequence upstream of the FaChit1 start codon did not activate GUS expression, whereas the 935 and 651 bp upstream sequences did. This suggests that the $418 \mathrm{bp}$ sequence between the 651 and $233 \mathrm{bp}$ fragments is essential for elicitor response. Moreover, the $284 \mathrm{bp}$ sequence between the 651 and 935 bp fragments, which contains two W boxes, seemed to enhance GUS activity. This is in agreement with previous reports that multiple $\mathrm{W}$ box sites had a synergistic effect on elicitor-mediated transcription activation, whereas a single W box had only a minor effect (Eulgem et al. 1999). Generally, WRKY binding sites occur with relatively high frequency in promoters of pathogen-induced genes (Chen et al. 2002). It is possible that $\mathrm{W}$ boxes serve as common cis-elements for plants in response to various pathogen infections and that specificity for each pathogen may be achieved by the combinatorial interactions between $\mathrm{W}$ boxes and other cis-acting elements through corresponding transcription factors (Sawant et al. 2005).

Although no typical dehydration response element binding site exists in the FaChit1 promoter, both the endogenous gene in tall fescue and promoter-GUS fusions in transgenic tobacco were strongly activated in response to dehydration stress. Stress-responsive genes often contain ABRE and MYC or MYB recognition sequences in their promoters (Chinnusamy et al. 2004). The FaChit1 promoter also has such elements, including more than ten MYB and MYC recognized sites, and four ABREs. We suggest that these elements are involved in the drought response of the FaChit1 promoter.

Ethylene acts as a signal molecule in response to many environmental cues. Although a typical ethylene responsive GCC box was not observed in the FaChit1 promoter, ethylene nonetheless activated each promoter construct in transgenic tobacco to different degrees. This is in agreement with the observation that some ethylene-induced genes do not contain GCC box in their promoters, such as for genes related to ripening and senescence (Chakravarthy et al. 2003; Pirrello et al. 2006). Moreover, some ethylene-induced transcription factors can activate promoters lacking GCC boxes, for instance, AtERF14 in Arabidopsis and Pti4 in tomato (Chakravarthy et al. 2003; Onate-Sanchez et al. 2007). This suggests that the FaChit1 promoter contains uncharacterized ethylene response elements.

In conclusion, the tall fescue turf grass class I chitinase gene FaChit1 is activated by fungal elicitors, dehydration, ethylene, and mechanical wounding. Potential stress-related regulatory elements such as W boxes, ABREs, and WRKY, MYB, and MYC binding elements were identified in FaChit1 $5^{\prime}$ upstream sequences. These potential cisacting elements may activate FaChit1 in response to environmental stresses and contribute to the process of 
defense reaction of tall fescue. Additional investigation of those regulatory elements and FaChit1 gene function will further our knowledge of plant defense mechanism in tall fescue and may contribute to improving disease resistance of this important turf grass and potentially other plant species.

\section{Notes}

\section{Acknowledgments}

We are grateful to Zhi-feng Zhang (Fourth Military Medical University, Xi'an, Shaanxi, China) for help with the GUS assays. This study was supported by the National Natural Science Foundation of China (grant number 30870194), the Natural Science Foundation of Shaanxi Province (grant number 2006C103), the Research Project of Provincial Key Laboratory of Shaanxi (grant numbers 04JS07 and 08JZ70), and the Scientific Research Project of the Education Department of Shaanxi Province (Grant numbers: 05JK304 and 08JK466).

\section{Supplementary material}

11105200886 MOESM1 ESM.doc (28 kb)

Table S1 Lists of primers used in different experiments (DOC $28.5 \mathrm{~KB}$ ).

11105200886 MOESM2 ESM.doc $(28 \mathrm{~kb})$

Fig. S1 Schematic representation of the FaChit1 promoter fragment and GUS fusion constructs used in transformation experiments. The length is calculated from the translation start code (+1) (DOC $27.5 \mathrm{~KB})$.

\section{References}

Ancillo G, Hoegen E, Kombrink E (2003) The promoter of the potato chitinase C gene directs expression to epidermal cells. Planta 217:566-576. doi: 10.1007/s00425-003-1029-0

Beintema JJ (1994) Structural features of plant chitinases and chitin binding proteins. FEBS Lett 350:159-163. doi: 10.1016/0014-5793(94)00753-5

Bevan M (1984) Binary Agrobacterium vectors for plant transformation. Nucleic Acids Res 12:8711-8721. doi: $10.1093 /$ nar/12.22.8711

Bradford MM (1976) A rapid sensitive method for the quantitation of microgram quantities of protein utilizing the principle of protein-dye binding. Anal Biochem 72:248-254. doi: 10.1016/0003-2697(76)90527-3

Bubier J, Schlappi M (2004) Cold induction of EARLI1, a putative Arabidopsis lipid transfer protein, is light and calcium dependent. Plant Cell Environ 27:929-936. doi: 10.1111/j.1365-3040.2004.01198.x

Busk PK, Pages M (1998) Regulation of abscisic acid-induced transcription. Plant Mol Biol 37:425-435. doi: $10.1023 / A: 1006058700720$

Chakravarthy S, Tuori RP, D'Ascenzo MD, Fobert PR (2003) The tomato transcription factor Pti4 regulates defense-related gene expression via GCC box and non-GCC box cis-elements. Plant Cell 15:3033-3050. doi: $10.1105 /$ tpc.017574

Chen C, Chen Z (2002) Potentiation of developmentally regulated plant defense response by AtWRKY18, a pathogen-induced Arabidopsis transcription factor. Plant Physiol 129:706-716. doi: 10.1104/pp.001057

Chen WQ, Provart NJ, Glazebrook J (2002) Expression profile matrix of Arabidopsis transcription factor genes suggests their putative functions in response to environmental stresses. Plant Cell 14(3):559-574. doi: $10.1105 /$ tpc. 010410

Chinnusamy V, Schumaker K, Zhu JK (2004) Molecular genetic perspectives on cross-talk and specificity in abiotic stress signaling in plants. J Exp Bot 55:225-236. doi: 10.1093/jxb/erh005

Chujo T, Kato T, Yamada K, Takai R (2008) Characterization of an elicitor-induced rice WRKY gene, OsWRKY71. Biosci Biotechnol Biochem 72(1):24-25. doi: 10.1271/bbb.70553 
Dong J, Chen C, Chen Z (2003) Expression profiles of the Arabidopsis WRKY gene superfamily during plant defense response. Plant Mol Biol 51(1):21-37. doi: 10.1023/A:1020780022549

Eulgem T, Rushto PJ, Schmelzer E (1999) Early unclear events in plant defense signaling: Rapid gene activation by WRKY transcription factor. EMBO J 18(17):4689-4699. doi: 10.1093/emboj/18.17.4689

Fan J, Wang H, Feng D, Liu B, Liu H, Wang J (2007) Molecular characterization of plant in Class I chitinase gene and its expression in response to infection by Gloeosporium musarum Cke and Massee and other abiotic stimuli. J Biochem 142(5):561-570. doi: 10.1093/jb/mvm171

Fukamizo T (2000) Chitinolytic enzymes: catalysis, substrate binding, and their application. Curr Protein Pept Sci 1(1):105-1024. doi: 10.2174/1389203003381450

Glazebrook J (2001) Genes controlling expression of defense responses Arabidopsis 2001 status. Curr Opin Plant Biol 4:301-308. doi: 10.1016/S1369-5266(00)00177-1

Gomez L, Allona I, Casado R, Aragoncillo C (2002) Seed chitinases. Seed Sci Res 12:217-30. doi: $10.1079 /$ SSR2002113

Hahn M, Henning M (2000) Structure of Jack bean chitinase. Acta Crystallogr D Biol Crystallogr 56:1096-1099. doi: $10.1107 / \mathrm{S} 090744490000857 \mathrm{X}$

Hong JK, Hwang BK (2006) Promoter activation of pepper Class II basic chitinase gene, CAChi2, and enhanced bacterial disease resistance and osmotic stress tolerance in the CAChi2-overexpressing Arabidopsis. Planta 223:433-448. doi: 10.1007/s00425-005-0099-6

Huet J, Rucktooa P, Clantin B, Azarkan M, Looze Y, Villeret V, Wintjens R (2008) X-ray structure of papaya chitinase reveals the substrate binding mode of glycosyl hydrolase family 19 chitinases. Biochemisty 47(32):8283-91. doi: 10.1021/bi800655u

Iseli B, Boller T, Neuhaus JM (1993) The N-terminal cysteine-rich domain of tobacco Class I chitinase is essential for chitin binding but not for catalytic or antifungal activity. Plant Physiol 103:221-226. doi: $10.1104 /$ pp.103.1.221

Jefferson RA, Kavanagh TA, Bevan MW (1987) GUS fusions: $\beta$-glucouronidase as a sensitive and versatile gene fusion marker in higher plants. EMBO J 13:3901-3907

Li WL, Faris JD, Chittoor JM, Leach JE, Liu DJ, Chen PD, Gill BS (1999) Genomic mapping of defense response genes in wheat. Theor Appl Genet 98:226-233. doi: 10.1007/s001220051062

Li WL, Faris JD, Muthukrishnan S (2001) Isolation and characterization of novel cDNA clones of acidic chitinase and $\beta-1,3$-glucanases from wheat spikes infected by Fusarium graminearum. Theor Appl Genet 102:353-362. doi: $10.1007 / \mathrm{s} 001220051653$

Mei XG, Liu L, Yu LJ (2000) Enhanced paclitaxel production induced by the combination of elicitors in cell suspension cultures of Taxus chinensis. Biotechnol Lett 22:1561-1564. doi: 10.1023/A:1005684901329

Nakano T, Nishiuchi T, Suzuki K, Fujimura T, Shinshi H (2006) Studies on transcriptional regulation of endogenous genes by ERF2 transcription factor in tobacco cells. Plant Cell Physiol 47(4):554-558. doi: $10.1093 / \mathrm{pcp} / \mathrm{pcj} 017$

Nakashima K, Fujita Y, Katsura K et al (2006) Transcriptional regulation of ABI3- and ABA-responsive genes including RD29B and RD29A in seeds, germinating embryos, and seedlings of Arabidopsis. Plant Mol Biol 60:51-68. doi: 10.1007/s11103-005-2418-5

Onate-Sanchez L, Anderson JP, Young J (2007) AtERF14, a member of the ERF family of transcription factors, plays a nonredundant role in plant defence. Plant Physiol 143:400-409. doi: 10.1104/pp.106.086637

Park HC, Kim ML, Kang YH (2004) Pathogen- and NaCl-induced expression of the SCaM-4 promoter is mediated in part by a GT-1 Box that interacts with a GT-1-Like transcription factor. Plant Physiol 135(4):21502161. doi: $10.1104 / p p .104 .041442$

Pirrello J, Jaimes-Miranda F, Sanchez-Ballesta MT (2006) S1-ERF2, a tomato ethylene response factor involved in ethylene response and seed germination. Plant Cell Physiol 47(9):1195-205. doi: 10.1093/pcp/pcj084 
Richter TE, Ronald PC (2000) The evolution of disease resistance genes. Plant Mol Biol 42:195-204. doi: $10.1023 / \mathrm{A}: 1006388223475$

Rogers SG, Horsch RB, Fraley RT (1988) Gene transfer in plants: production of transformed plants using Ti plasmid vectors. In: Weissbach A, Weissbach H (eds) Methods for plant molecular biology. Academic, New York, pp 425-436

Sambrook J, Russell DW (2001) Molecular cloning, a laboratory manual. Cold Spring harbor Laboratory, Cold Spring Harbor

Salzman RA, Brady JA, Finlayson SA (2005) Transcriptional profiling of sorghum induced by methyl jasmonate, salicylic acid, and aminocyclopropane carboxylic acid reveals cooperative regulation and novel gene responses. Plant Physiol 138:352-368. doi: 10.1104/pp.104.058206

Sawant SV, Kiran K, Mehrotra R et al (2005) A variety of synergistic and antagonistic interactions mediated by cis-acting DNA motifs regulate gene expression in plant cells and modulate stability of the transcription complex formed on a basal promoter. J Exp Bot 56(419):2345-53. doi: 10.1093/jxb/eri227

Shinshi H, Usami S, Ohme-Takagi M (1995) Identification of an ethylene responsive region in the promoter of a tobacco Class I chitinase gene. Plant Mol Biol 27:923-932. doi: 10.1007/BF00037020

Somssich IE, Hahlbrock K (1998) Pathogen defense in plants-a paradigm of biological complexity. Trends Plant Sci 3(3):86-90. doi: 10.1016/S1360-1385(98)01199-6

Stewart CN Jr, Via LE (1993) A rapid CTAB DNA isolation technique useful for RAPD fingerprinting and other PCR application. Biotechniques 14:748-750

Takakura Y, Ito T, Saito H, Inoue T, Komari T, Kuwata S (2000) Flower-predominant expression of a gene encoding a novel Class I chitinase in rice (Oryza sativa L). Plant Mol Biol 42:883-897. doi: $10.1023 / \mathrm{A}: 1006401816145$

Tateishi Y, Umemura Y, Esaka M (2001) A basic Class I chitinase expression in winged bean is up-regulated by osmotic stress. Biosci Biotechnol Biochem 75(7):1663-168. doi: 10.1271/bbb.65.1663

Thatcher LF, Anderson JP, Singh KB (2005) Plant defense response: what have we learnt from Arabidopsis. Funct Plant Biol 32:1-19. doi: 10.1071/FP04135

Tran LS, Nakashima K, Sakuma Y, Simpson SD, Fujita Y, Maruyama K (2004) Isolation and functional analysis of Arabidopsis stress-inducible NAC transcription factors that bind to a drought-responsive cis-element in the early responsive to dehydration stress promoter. Plant Cell 16:2481-2498. doi: $10.1105 /$ tpc.104.022699

Urao T, Yamaguchi-Shinozaki K, Urao S (1993) An Arabidopsis myb homolog is induced by dehydration stress and its gene product binds to the conserved MYB recognition sequence. Plant Cell 5:1529-1539

Wu H, Michler CH, LaRussa L, Davis JM (1999) The pine Pschi4 promoter directs wound-induced transcription. Plant Sci 142:199-207. doi: 10.1016/S0168-9452(99)00009-6

Xiao YH, Li XB, Yang XY (2007) Cloning and characterization of a Balsam pear Class I chitinase gene (Mcchit1) and its ectopic expression enhances fungal resistance in transgenic plants. Biosci Biotechnol Biochem 71(5):1211-1219. doi: $10.1271 /$ bbb.60658

Xu X, Chen C, Fan B, Chen Z (2006) Physical and functional interactions between pathogeninduced Arabidopsis WRKY18, WRKY40, and WRKY60 transcription factors. Plant Cell 18:1310-1326. doi: $10.1105 /$ tpc.105.037523

Yamamoto S, Nakano T, Suzuki K, Shinshi H (2004) Elicitor-induced activation of transcription via W boxrelated cis-acting elements from a basic chitinase gene by WRKY transcription factors in tobacco. Biochim Biophys Acta 1679:279-287

Yang P, Wang Z, Fan B, Chen C, Chen Z (1999) A pathogen- and salicylic acid-induced WRKY DNA-binding activity recognizes the elicitor response element of the tobacco Class I chitinase gene. Plant J 18:141-149. doi: 10.1046/j.1365-313X.1999.00437.x 